\title{
Polikistik over sendromunda androjen seviyeleri ve seksüel disfonksiyon
}

\author{
Androgen levels and sexual dysfunction in polycystic ovary syndrome
}

\author{
Rümeysa Selvinaz Erol, Pınar Kadıoğlu²®
}

\section{öz}

AMAC̦: Poliskistik over sendromunda (PKOS) seksüel fonksiyonun sorgulanmasını ve seksüel fonksiyonun andojen seviyeleri ile ilişkisini saptamayı amaçladık.

GEREC ve YÖNTEMLER: Yirmi beș PKOS tanılı hasta ve yaş, cins uyumlu 25 kontrol çalışmaya alındı. Kontrol ve hasta grubundaki bireylere Kadın Seksüel Fonksiyon İndeksi (FSFI) ve Beck Depresyon Anketi (BDA) yapıldı. Katılımcilardan serbest testosteron, total testosteron, dihidroepiandrostenodion sülfat (DHEA-S), androstenedion, prolaktin, seks hormon bağlayıcı globülin (SHBG), follikül uyaran hormon (FSH), luteinizan hormon (LH) ve östradiol ölçümleri için örnekler alınd. Serbest androjen indeksi (SAİ) hesaplanıldı. PKOS hasta grubu ve kontrol grubu arasında bu değerler karşılaştırıldı.

BULGULAR: PKOS hasta grubunun total FSFI skoru 26,17 \pm 4 iken

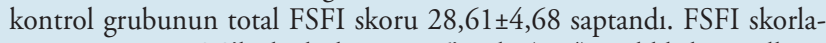
masına göre PKOS'lu kadınların \%16'sında $(\mathrm{n}=4)$ sağlıklı kontrollerin $\% 20$ 'sinde $(\mathrm{n}=5)$ seksüel disfonksiyon tespit edildi $(\mathrm{p}=0,57)$. PKOS grubu ile kontrol grubu arasında seksüel istek $(\mathrm{p}=0,89)$, uyarılma $(\mathrm{p}=0,10)$, lubrikasyon $(\mathrm{p}=0,057)$, orgazm $(\mathrm{p}=0,18)$ ve tatmin $(\mathrm{p}=0,78)$ skorlamaları arasında fark olmadığı, seksüel ağrı skorlamasının $(\mathrm{p}=0,002)$ ise PKOS'lu kadınlarda anlamlı oranda düşük olduğu belirlendi. PKOS grubunda kontrol grubuna göre BDA skorlaması anlamlı oranda yüksek bulundu $(\mathrm{p}=0,002)$. Androjen seviyeleri ve SAİ ile total FSFI ve FSFI alt alanları arasında korelasyon saptanmadı.

SONUCุ: Sonuç olarak, PKOS hastalarında seksüel istek, uyarılma, lubrikasyon, tatmin ve orgazm bozuklukları ile ilgili skorlar, kontrol bireylerdekine benzer, depresyon ile ilgili skorlar ise kontrol bireylere göre daha yüksek görülmektedir. Total FSFI, istek, uyarılma, lubrikasyon, orgazm, seksüel tatmin skorlamaları ile androjen seviyeleri arasında korelasyon tespit edilmemiştir.

Anahtar Kelimeler: Kadın seksüel fonksiyon indeksi, kadın cinsel fonksiyon bozukluğu, polikistik over sendromu, androjenler

\section{ABSTRACT}

OBJECTIVE: We aimed to examine sexual function and relationship between sexual function and androgen levels in polycystic ovary syndrome (PCOS).

MATERIAL and METHODS: Twenty-five patients diagnosed with PCOS and 25 age, gender-matched controls were enrolled into the study. Subjects were evaluated with female sexual function index (FSFI) and Beck Depression Inventory (BDI) questionnaires. Free testosterone, total testosterone, dehydroepiandrosterone sulfate (DHEA-SO4), androstenedione, prolactin, sex hormone binding globulin (SHBG), follicle-stimulating hormone (FSH), luteinizing hormone (LH) and estradiol levels were measured and free androgen index (FAI) was calculated. We compared between patients and control groups these values.

RESULTS: Total FSFI score $26.17 \pm 4$ was in the PCOS group whereas, healthy women had a total FSFI score of $28.61 \pm 4.68$. FSD was diagnosed in 4 of 25 patients (\% 16) while 5 of 25 (\% 20) healthy women had FSD ( $\mathrm{p}=0.57)$. There is no statistically significant difference between sexual desire $(\mathrm{p}=0.89)$, arousal $(\mathrm{p}=0.10)$, lubrication $(\mathrm{p}=0.057)$, $\operatorname{orgasm}(\mathrm{p}=0.18)$ and satisfaction domain $(\mathrm{p}=0.78)$ scores. The sexual pain score $(\mathrm{p}=0.002)$ was found to be significantly lower in women with PCOS. BDI scores was significantly higher in PCOS women $(\mathrm{p}=0.002)$. No correlation was seen between androgen level and FAI and total FSFI score and domain score.

CONCLUSION: Scores related to sexual desire, arousal, lubrication, satisfaction and orgasm disorders in PCOS patients are similar to those of control individuals, while scores for depression are higher than control individuals. No correlation was found between total FSFI, desire, arousal, lubrication, orgasm, sexual satisfaction scores and androgen levels.

Keywords: Female sexual function index, female sexual dysfunction, polycystic ovary syndrome, androgens
'Sağlık Bilimleri Üniversitesi, Şişli Hamidiye Etfal Eğitim ve Araştırma Hastanesi, Endokrinoloji ve Metabolizma Hastalıkları Kliniği, Seyrantepe- İstanbul, Türkiye ${ }^{2}$ Cerrahpaşa Tıp Fakültesi, İstanbul Üniversitesi, Cerrahpaşa, İç Hastalıkları Anabilim Dalı, Endokrinoloji, Metabolizma ve Diyabet Bilim Dalı, İstanbul, Türkiye

\section{Yazıșma Adresi/ Correspondence:}

Uzm. Dr. Selvinaz Rümeysa Erol

Sağlık Bilimleri Üniversitesi, Şş̧li Hamidiye Etfal Eğitim Araştırma Hastanesi,

Seyrantepe, 34396, İstanbul, Türkiye

Tel: $\quad$ +905302360867

E-mail: drselvinazerol@gmail.com

Gelis/ Received: $\quad 30.09 .2021$

Kabul/ Accepted: $\quad 02.11 .2021$

\section{Gíriș}

Polikistik over sendromu (PKOS) etiyolojisi kesin olarak bilinmeyen heterojen bir bozukluktur ve kullanılan tanı kriterlerine göre, doğurganlık çağındaki kadınlarda \%5-20 oranında görülmektedir. ${ }^{[1,2]}$ PKOS etyopatogenezinde ileri sürülen hipotezlerden birkaçı primer nöroendokrin defekt sonucu abartılı luteinizan hormon (LH) pulse frekansı ve amplitüdü, androjen sentezindeki defekt sonucu artmış over kaynaklı androjen ürünleri ve kortizol 
metabolizmasındaki değişikliklere bağlı adrenal kaynaklı artmış androjenler olarak sayılabilir. ${ }^{[1,3]}$

2003 Roterdam kriterlerine göre PKOS tanısı, klinik ve/ veya biyokimyasal hiperandrojenizm, oligoamenore ve/veya amenore ve polikistik over morfolojisi bulgularından iki tanesinin olması ile koyulmaktadır. ${ }^{[4]}$ Hiperandrojenizm, PKOS'un en belirgin ve değişmez komponentlerinden biridir ve hirsutizm, akne, erkek tipi kellik ve bazı ciddi vakalarda da kliteromegali kliniği ile karşımıza çıkmaktadır. Hirsutizm en yaygın görülen semptomdur ve PKOS’lu kadınların yaklaşık \%60'ında görülmektedir. ${ }^{[1,5]}$ Hiperandrojeneminin değerlendirilmesinde serum total testosteron, serbest testosteron, androstenedion ve dihidroepiandrostenodion sülfat (DHAE-S)) kullanılmaktadır. ${ }^{[5]}$

Androjenlerin, kadın seksüel siklusdaki, seksüel istek üzerine etki gösterdiğine dair ortak bir görüş vardır. ${ }^{[6-8]}$ Yapılan çalışmalarda da seksüel istekte azalması olan kadınlarda testosteron seviyesinin düşük olduğu saptanmış ve testosteron replasmanı ile seksüel isteklerinde düzelme olduğu tespit edilmiştir. ${ }^{[9-11]}$ Hiperandrojenemi, PKOS tanısının değişmez bir bulgusudur ve androjen yüksekliğine bağlı olarak seksüel istekte artma olması beklenilebilir. ${ }^{[5,12]}$ Ama hastalığa bağlı olarak kadınsı kimliklerinde azalmaya neden olan dış görünüşlerinden dolayı özgüvenlerinde azalma ve eşlik eden depresyon gibi psikolojik bozukluklarının olması nedeniyle seksüel fonksiyon bozuklukları da görülebilmektedir. ${ }^{[13-15]}$ Bununla birlikte, doğurma çağındaki kadınlarda en sık görülen endokrinolojik hastalık olan PKOS'un seksüel fonksiyon üzerine etkilerini araştıran çalışmalar nispeten az sayıda olup sonuçları da tartışmalıdır.

Seksüel fonksiyonun hayat kalitesi üzerine önemli etkilerinden dolayı PKOS'lu kadınlarda seksüel fonksiyonun sorgulanmasını ve seksüel fonksiyon ile androjen seviyeleri arasındaki ilişkiyi saptamayı amaçladık.

\section{GEREÇ ve YÖNTEMLER}

\section{Hasta Seçimi}

Çalışmamız vaka kontrol çalışması olarak tasarlanmıştır. Ocak 2009-Haziran 2009 tarihleri arasında Cerrahpaşa Tıp Fakültesi, Endokrinoloji Diyabet ve Metabolizma Polikliniği'nde takip ve tedavi edilen, 2003 Roterdam kriterlerine göre PKOS tanısı konulmuş 20-40 yaş arasında, son bir yıldır aynı partner ile düzenli seksüel hayatı olan 25 aktif kadın çalışmaya alındı. ${ }^{[4]}$ Hiperandrojenizmin laboratuvar bulguları olmayanlar, düzenli seksüel hayatı olmayanlar, kronik hastalığı olanlar, son üç ay içerisinde adet düzensizliği ve/veya hirsutizm nedeniyle hormon temelli kontraseptif, siproteran asetat ve spironolakton gibi antiandrojen ilaç ve antidepresen ilaç alanlar çalışmaya alınmadı. Yaş ve cins uyumlu, sistemik hastalığı bulunmayan, son bir yıldır düzenli cinsel hayatı olan, menstrüel siklusları düzenli ve hirsutizm yakınması olmayan hastane çalışanı gönüllü kişilerden 25 kontrol grubu seçildi. Her iki gruptaki bireylere çalışma içeriği anlatılıp yazılı onamları alınd.

Kontrol ve hasta grubundaki bireylere Kadın Seksüel Fonksiyon İndeksi (FSFI) ve Beck Depresyon Anketi (BDA) yapıldı. Katılımcılardan FSFI ve BDA anketlerini kendi kendilerine doldurmaları ve doldurduktan sonra kapalı bir zarfa koymaları istendi. Ayrıca katılımcılara bilgilerinin gizli kalacağı ve çalışmaya katılmayı reddetmeleri durumunda ise tedavilerinin etkilenmeyeceği anlatıldı.

PKOS ve kontrol grubunun vücut kitle indeksi (VKİ) hesaplanıldı. Hirsutizm, Ferriman- Gallwey skorlamasına göre değerlendirildi.

\section{FSFI ve BDA Değerlendirilmesi}

FSFI, toplam 19 sorudan oluşmaktadır ve son dört hafta boyunca olan seksüel fonksiyonu değerlendirmektedir. FSFI, seksüel fonksiyonu seksüel istek, uyarılma, vajinal lubrikasyon, orgazm, seksüel tatmin ve seksüel ağrı olmak üzere 6 bölümde ele almaktadır. Her bir soru için skorlamalar 0-5 veya 1-5 arasında yapılmaktadır. İlk üç soruda seksüel isteğin sıklığı ve seviyesi değerlendirilmektedir. Takip eden dört soruda seksüel uyarılmanın sıklığı, seviyesi, tatmin ediciliği ve uyarılmadan emin olunup olunmaması sorgulanmaktadır. Sonraki dört soru ile vajinal lubrikasyonun sıklığı, zorluğu, lubrikasyonun korunmasındaki sıklık ve zorluk derecesi değerlendirilmektedir. On birinci ve 13 . sorular arasında orgazmın sıklığı, zorluğu ve tatmin ediciliği sorgulanmaktadır. 14 ve 16 . sorular arasında partneri ile olan duygusal yakınlığın, seksüel ilişkinin ve tüm cinsel hayatın tatmin ediciliği değerlendirilmektedir. Son üç soruda ise seksüel ilişki sırasında ve sonrasındaki ağrı sıklığı sorgulanmaktadır. Total FSFI skorlaması en az iki ve en fazla 36 puandir. ${ }^{[16]}$ Total FSFI skorunun 22,7'in altında olması seksüel disfonksiyon olarak kabul edildi. FSFI'nın alt alanlarının (istek, uyarılma, lubrikasyon, orgazm, seksüel tatmin ve seksüel ağrı) skorlamaları hesaplanıldı. Seksüel istek bölümünün skoru 3,6'dan küçük ise cinsel istek azlığı olarak, uyarılma bölümünün skoru 3,9'dan küçük ise uyarılma bozukluğu olarak, lubrikasyon bölümünün skoru 3,6'dan küçük ise lubrikasyon bozukluğu olarak, orgazm bölümünün skoru 3,6'dan küçük ise orgazm bozukluğu olarak, seksüel tatmin bölümünün skoru 3,6'dan küçük ise seksüel tatminsizlik olarak, seksüel ağrı bölümünün skoru 4’den küçük ise seksüel ağrı bozukluğu olarak kabul edildi. ${ }^{[17]}$ 
Beck depresyon anketi, üzgünlük, kendini sevmeme, kötümserlik ve yorgunluk gibi depresyon semptomlarını ve karakteristik özelliklerini ölçen, toplam 21 sorudan oluşan, kendi kendine uygulanabilen bir testtir. BDA'nın her bir sorudaki skorları 0-3 arasındadır. Maksimum puan 63'dür.

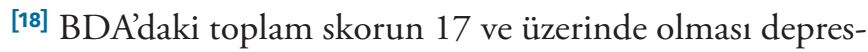
yon olarak kabul edildi. Her iki anketin de Türk populasyonunda validasyonu yapılmıştır. Her iki anket de tek bir araştırmacı tarafından değerlendirildi.

\section{Biyokimyasal Değerlendirme}

Hasta ve sağlıklı kontrol grubundan erken foliküler fazda sabah saat 10:00'dan önce serbest testosteron, total testosteron, DHEA-S, androstenedion, prolaktin, seks hormon bağlayıcı globülin (SHBG), follikül uyaran hormon (FSH), LH ve östradiol ölçümleri için kan örnekleri alındı. Alınan kan örnekleri santrifüj edilip serumları ayrıldıktan sonra, ölçüm zamanına kadar $-80^{\circ} \mathrm{C}$ lik dondurucuda sakland. Prolaktin (normal: 5,18-26,53 ng/ml), total testosteron (normal: $15-70 \mathrm{ng} / \mathrm{dl}$ ), SHBG (normal: 19,8-155,2 nmol/l) ve DHEA-S (20-24 yaş arası normal: 134,2$407,4 \mu \mathrm{g} / \mathrm{dl}, 25-34$ yaş arası normal: 95,8-511,7 $\mu \mathrm{g} / \mathrm{dl}$, 35-44 yaş arası normal: 74,8-410,2 $\mu \mathrm{g} / \mathrm{dl}$ ) chemiluminescence immunoassay yöntemiyle ölçüldü. Androstenedion (normal: $0,1-2,99 \mathrm{ng} / \mathrm{ml}$ ) ve serbest testosteron (normal: $0,45-3,17 \mathrm{pg} / \mathrm{ml}$ ) radioimmunoassay yöntemiyle ölçüldü. Serbest androjen indeksi (normal: \%0,5-7,3) total testosteron $\mathrm{nmol} / \mathrm{l} \div \mathrm{SHBG} \mathrm{nmol} / \mathrm{l} \times 100$ şeklinde hesaplandı.

\section{Etik Onay}

İstanbul Üniversitesi, Cerrrahpaşa Tip Fakültesi Etik Kurulu'ndan onay alındı. (Onay tarihi 06.01.2009 numarası: 3935)

\section{İstatistiksel Analiz}

Verilerin istatiksel değerlendirilmesinde SPSS 13.0 istatistiki paket programı kullanıldı. Gruplar arasında niteliksel verilerin karşılaştırılmasında Ki-kare testi, parametrik verilerin ortalamalarının karşılaştırılmasında Student-t, nonparametrik verilerin ortancalarının karşılaştırılmasında Mann-Whitney U testi ve değişkenler arasındaki korelasyonun değerlendirilmesinde Pearson korelasyon testi kullanıldı. P değerinin 0,05’ten küçük olması istatistiki olarak anlamlı kabul edildi.

\section{BULGULAR}

Hasta ve kontrol grubunun yaş, VKİ ve Ferriman-Gallwey skorlamalarının karşılaştırılması Tablo 1'de gösterilmiştir. Çalışmaya alınan hastaların \%36'sında (n=9) amenore, \%52'sinde $(\mathrm{n}=13)$ oligoamenore gibi menstrüel
Tablo 1. Hasta ve kontrol grubunun yaş, VKI ve FerrimanGallwey skorlamaları

\begin{tabular}{lccc}
\hline & PKOS grubu & Kontrol grubu & $p$ \\
\hline & $(n=25)$ & $(n=25)$ \\
\hline Yaş & $28,8 \pm 4,8$ & $30,4 \pm 5,2$ & 0,26 \\
VKi & $27,58 \pm 3,88$ & $22,25 \pm 3,08$ & 0,001 \\
Ferriman-Gallwey & $11,3 \pm 3,15$ & $4,2 \pm 1,11$ & 0,001 \\
\hline
\end{tabular}

VKi, Vücut Kitle İndeksi

düzensizlik semptomları ve $\% 52$ 'sinde $(\mathrm{n}=13)$ polikistik over morfolojisi mevcuttu. PKOS grubundaki hastaların \%24'ünün ( $\mathrm{n}=6$ ) VKİ'si $30 \mathrm{~kg} / \mathrm{m}^{2}$ 'den büyük, \%52'sinin (n=13) VKİsi $25 \mathrm{~kg} / \mathrm{m}^{2}$ ile $30 \mathrm{~kg} / \mathrm{m}^{2}$ arasında, \%24'ünün (n=6) VKİ'si $25 \mathrm{~kg} / \mathrm{m}^{2}$ 'den küçük olarak saptandı.

PKOS grubundaki hastaların hormon seviyeleri kontrollerle karşılaştırıldığında anlamlı olarak yüksek, SHBG $(\mathrm{p}=0,001)$ seviyesinin ise anlamlı olarak düşük olduğu görüldü. Her iki grup arasında serum prolaktin seviyeleri $(\mathrm{p}=0,2)$ arasında anlamlı fark tespit edilmedi. PKOS grubunda hesaplanılan serbest androjen indeks yüzdesi $(\mathrm{p}=0,001)$ anlamlı olarak yüksek bulundu. Hasta ve kontrol grubunun serum hormon seviyeleri, SHBG ve serbest androjen indeksinin (SAİ) karşılaştırılmaları Tablo 2'de gösterilmiştir.

Tablo 2. Hasta ve kontrol grubundaki hormon seviyeleri, SHBG ve SAi

\begin{tabular}{|c|c|c|c|}
\hline & $\begin{array}{c}\text { PKOS } \\
(n=25) \\
\text { Ortanca ÇAA }\end{array}$ & $\begin{array}{l}\text { Kontrol grubu } \\
\quad(n=25) \\
\text { Ortanca ÇAA }\end{array}$ & $p$ \\
\hline $\begin{array}{l}\text { Testosteron } \\
\text { (ng/dl) }\end{array}$ & 85 77,5-119,75 & 38 30,55-56,66 & 0,001 \\
\hline $\begin{array}{l}\text { Serbest testosteron } \\
(\mathrm{pg} / \mathrm{ml})\end{array}$ & $3,282,78-3,85$ & 1,65 1,31-1,89 & 0,001 \\
\hline $\begin{array}{l}\text { DHEA-SO4 } \\
(\mu \mathrm{g} / \mathrm{dl})\end{array}$ & $369,8306,3-487,8$ & 247 179,9-320,7 & 0,001 \\
\hline $\begin{array}{l}\text { Androstenedion } \\
(\mathrm{ng} / \mathrm{ml})\end{array}$ & 4,325 2,88-5,36 & 1,87 1,49-2,17 & 0,001 \\
\hline SHBG (nmol/l) & $32,822,17-50,22$ & $59,2.43,8-79,37$ & 0,001 \\
\hline Prolaktin (ng/ml) & $12,367,72-15,49$ & $14,368,77-18,49$ & 0,2 \\
\hline SAI & $8,676,31-16$ & $2,351,34-4,19$ & 0,001 \\
\hline
\end{tabular}

SAi, Serbest Androjen İndeksi; ÇAA, Çeyrekler Arası Aralık (25. ve 75. persentiller arası)

Total FSFI skorlamasına göre PKOS hasta grubunun \%16'sinda ( $\mathrm{n}=4)$, kontrol grubunun \%20'sinde $(\mathrm{n}=5)$ seksüel disfonksiyon olduğu tespit edildi. Her iki grup karşılaştırıldığında ise aralarında anlamlı fark olmadığı belirlendi $(\mathrm{p}=0,57)$. FSFI'nın her bir alt alanı teker teker incelendiğinde PKOS grubunda istek bozukluğu \%16 $(\mathrm{n}=4)$, uyarılma bozukluğu \%24 (n=6), lubrikasyon bozukluğu \%4 $(\mathrm{n}=1)$, orgazm bozukluğu \%20 ( $\mathrm{n}=5)$, seksüel tatminsizlik $\% 12$ $(\mathrm{n}=3)$ seksüel ağrı bozukluğu \%44 ( $\mathrm{n}=11)$ olarak saptandı. Kontrol grubunda ise istek bozukluğu \%28 ( $\mathrm{n}=7)$, uyarılma 
bozukluğu \%24 ( $n=6)$, lubrikasyon bozukluğu \%0 ( $n=0)$, orgazm bozukluğu \%12 ( $\mathrm{n}=3)$, seksüel tatminsizlik \%8 $(n=2)$, seksüel ağrı bozukluğu \%8 (n=2) olarak bulundu.

Her iki grup arasında istek $(p=0,89)$, uyarılma $(p=0,10)$, lubrikasyon $(\mathrm{p}=0,57)$ seksüel tatmin $(\mathrm{p}=0,78)$ ve orgazm $(\mathrm{p}=0,18)$ skorlamaları arasında anlamlı fark tespit edilmedi. PKOS’lu hastalar kontrol grubuyla karşılaştırıldığında seksüel ağrı skorlamasının PKOS grubunda anlamlı olarak düşük olduğu belirlendi $(\mathrm{p}=0,02)$. Hasta ve kontrol grubunun total FSFI, istek, uyarılma, lubrikasyon, orgazm, seksüel tatmin ve ağrı skorlamalarının karşılaştırılması Tablo 3'te gösterilmiştir.

BDA ile PKOS grubundaki hastaların \%52'sinde $(n=13)$, kontrol grubundakilerin ise \%24'ünde $(n=6)$ depresyon saptandı. Her iki grup karşılaştırıldığında PKOS grubunda BDA skorlaması $(\mathrm{p}=0,002)$ anlamlı olarak yüksek bulundu. Hasta ve kontrol grubunun BDA skorlamasının karşılaştırılması Tablo 3'te gösterilmiştir.

Tablo 3. Hasta ve kontrol grubundaki FSFI ve BDA skorlamaları

\begin{tabular}{lccc}
\hline & $\begin{array}{c}\text { PKOS grubu } \\
(n=25)\end{array}$ & $\begin{array}{c}\text { Kontrol grubu } \\
(n=25)\end{array}$ & $P$ \\
\hline BDA & $17 \pm 7,34$ & $10,24 \pm 7,44$ & 0,002 \\
FSFI & $26,17 \pm 4,00$ & $28,61 \pm 4,68$ & 0,57 \\
İstek & $3,8 \pm 0,82$ & $3,76 \pm 0,89$ & 0,89 \\
Uyarılma & $4,23 \pm 0,93$ & $4,69 \pm 0,97$ & 0,10 \\
Lubrikasyon & $4,78 \pm 0,88$ & $5,24 \pm 0,75$ & 0,05 \\
Orgazm & $4,31 \pm 1,16$ & $4,75 \pm 1,11$ & 0,18 \\
Seksüel tat- & 4.831 .06 & $4,91 \pm 0,90$ & 0,78 \\
min & $4,2 \pm 1,35$ & $5,24 \pm 0,89$ & 0,002 \\
Seksüel ağrı &
\end{tabular}

FSFI, Kadın Seksüel Fonksiyon İndeksi; BDA, Beck Depresyon Anketi

PKOS grubunun total FSFI, istek, uyarılma, lubrikasyon, orgazm, seksüel tatmin skorlamaları ile androjen seviyeleri arasında korelasyon tespit edilmedi. PKOS hasta grubunun total FSFI skorlaması ve androjen düzeyleri arasındaki korelasyon bulguları Tablo 4'te gösterilmiştir.

Tablo 4. PKOS'lu hastalarda serum androjen düzeyleri ve total FSFI skorlaması arasındaki korelasyon bulguları

\begin{tabular}{lcc}
\hline & $r$ & $p$ \\
\hline Testosteron $(\mathrm{ng} / \mathrm{dl})$ & $-0,142$ & 0,16 \\
Serbest Testosteron $(\mathrm{pg} / \mathrm{ml})$ & 0,367 & 0,27 \\
DHEA-SO4 $(\mu \mathrm{g} / \mathrm{dl})$ & 0,435 & 0,12 \\
Androstenedion $(\mathrm{ng} / \mathrm{ml})$ & $-0,675$ & 0,56 \\
SHBG $(\mathrm{nmol} / \mathrm{l})$ & $-0,897$ & 0,37 \\
SAi & $-0,162$ & 0,76 \\
\hline
\end{tabular}

SAi, Serbest Androjen Indeksi; DHEA-SO4, Dihidroepiandrostenodion Sülfat

\section{TARTIȘMA}

PKOS tanılı hastalarda seksüel disfonksiyon, kontrol grubuna göre benzer oranda görüldü. Ayrıca PKOS'lu hastalarla kontrol grubu arasında, FSFI'nın alt alanlarını oluşturan seksüel ağrı hariç seksüel istek, uyarılma, lubrikasyon, orgazm ve tatmin skorlamaları arasında istatiksel olarak anlamlı fark olmadığı tespit edildi. Kontrol grubu ile karşılaştırıldığında PKOS’lu kadınlarda depresyonun daha yaygın olduğu görüldü. Serum androjen seviyeleri ve serbest androjen indeksi (SAİ) ile total FSFI ve FSFI'nın alt alan skorlamaları arasında korelasyon saptanmadı.

Literatürde PKOS hasta grubunun iki temel bulgusu olan obezite ve hirsutizm'in seksüel fonksiyon üzerine etkilerini gösteren çok sayıda çalışma bulunmaktadır. Bazı yazarlar, PKOS hastalarında hirsutizm ve obezitenin cinsel işlev için olumsuz risk faktörleri olduğunu göstermişlerdir. ${ }^{[19,20]}$ Diğerleri, hirsutizm ve obezitenin seksüel fonksiyon üzerine olumsuz bir etkisi olmadığını bulmuşlardır. ${ }^{\text {[20-22] }}$

Anger ve ark. FSFI' 1 sadece istek, uyarılma, lubrikasyon ve orgazm alt alanlarını değerlendirdikleri çalışmasında bizim çalışmamıza zıt olarak PKOS tanılı hastalarda yaygın oranda seksüel disfonksiyon olduğunu bulmuşlardır. Ayrıca VKİ ile seksüel disfonksiyon arasında da korelasyon olduğunu saptamışlardır. ${ }^{[19]}$ Elsenbruch ve ark. PKOS'lu kadınların hayat kalitelerini ve seksüel tatminlerini değerlendirmek için yaptıkları çalışmada ise PKOS’lu kadınların normal sağlıklı kontrollere göre kendilerini daha az çekici bulduklarını ve seksüel hayatlarında daha az tatmin olduklarını saptamışlardır. ${ }^{[20]}$ Aynı zamanda PKOS’lu kadınlarda obezitenin, seksüel ilişki sıklığı, seksüel düşünce, fanteziler ve seksüel tatmin üzerine etki yapmadığını tespit etmişlerdir. ${ }^{[2,23]}$ Hirsutizmin de PKOS’lu kadınlarda seksüel hayatı olumsuz yönde etkilediği gösterilmiştir. ${ }^{[20,24]}$ Ayrıca PKOS’lu kadınlarda seksüel disfonksiyon sıklığının artmış olduğu ama hirsutizmin seksüel disfonksiyon için bir risk faktörü olmadığı saptanmıştır. [21]

Hahn ve ark. PKOS'lu hastaların seksüel hayatlarında tatminsizlik yaşadığını saptamış ve obezite ile hirsutizmin seksüel hayatlarını olumsuz yönde etkilediğini göstermişlerdir. ${ }^{[25]}$ Ayrıca obezitenin PKOS olmaksızın sağlıklı kontrollerde seksüel fonksiyon üzerine olumsuz etkileri olduğu da bulunmuştur. ${ }^{[26]}$ PKOS'lularda obezitenin seksüel disfonksiyona etki eden faktörlerden biri olarak görüldüğü çalışmalarda hastaların VKİ ortalamalası $30 \mathrm{~kg} / \mathrm{m}^{2}$ den büyüktür ve çalışmamızda VKİ ortalamasının $27,58 \mathrm{~kg} /$ $\mathrm{m}^{2}$ olması obezitenin, seksüel fonksiyon üzerine olumsuz etkisini sınırlamış olabilir.

Popülasyonu temel alan bir çalışmada PKOS'lu kadınlardaki seksüel disfonksiyon sıklığının sağlıklı kontrol ile benzer olduğu saptanmıştır. ${ }^{[27]}$ Ülkemizde yapılan diğer 
bir çalışmada da çalışmamıza benzer olarak PKOS'lu hastalarla kontrol grubu arasında, FSFI'nın alt alanlarını oluşturan seksüel ağrı, seksüel istek, uyarılma, lubrikasyon, orgazm ve tatmin skorlamaları arasında istatistiksel olarak anlamlı fark olmadığı tespit edilmiş ve istatistiksel olarak olmasa da FSFI'n istek alt alan skorunun PKOS'lu kadınlarda daha yüksek olduğu gözlemlenmiştir. ${ }^{[28]}$ Seksüel fonksiyon değerlendirmek için farklı bir skorlama sistemi kullanılan çalışmalarda bile PKOS'lu kadınlar ile sağlıklı kontrol arasında orgazm ve total skor hariç diğer skorlar arasında anlamlı fark bulunmamıştır. [24] Obez olmayan PKOS'lu kadınlar, sağlıklı kontrol grubu ile karşılaştırıldığında PKOS hasta grubunda seksüel disfonksiyon saptanmamış ve orta derecede hirsutizmin de seksüel çekiciliği etkilemediği ve seksüel tatminsizliğe de neden olmadığı tespit edilmiştir. ${ }^{[22]}$ Buna sebep olarak da Akdeniz ülkesi olması sebebiyle daha kuzeydeki toplumlara göre İtalya'da artmış kıllanmanın fazla görülmesinin etkisi olabileceği öne sürülmüştür. Hirsutizmin daha fazla görüldüğü toplumsal özelliklerimizden dolayı diğer çalışmalarla benzer şekilde bizim çalışmamızda da hirsutizmin PKOS'lu kadınlarda seksüel fonksiyon üzerine olumsuz etki yapmadığını düşünmekteyiz. ${ }^{[29]}$

Depresyon, kadınlarda düşük libidoya neden olabilecek faktörlerden biridir. ${ }^{[30,31]}$ Birçok çalısmada, çalışmamızla uyumlu olarak PKOS'lu kadınlarda sağlıklı kontrollere göre yaygın oranda depresyon olduğu saptanmıştır. ${ }^{[20,25,32-34]}$ Nappi ve ark. obez olmayan 25 PKOS'lu hasta ve 18 sağlıklı kontrol grubunda yaptıkları Beck depresyon anketinde, her iki grup arasında depresyon açısından anlamlı fark olmadığını tespit etmişlerdir. ${ }^{[22]}$ Rasgon ve ark.32 PKOS’lu kadında depresyonun VKİ ile ilişkili olduğunu göstermişlerdir. ${ }^{[35]}$ Tek başına obezitenin diğer klinik semptomlardan bağımsız olarak sağlıklı insanlarda bile depresyona neden olabileceği literatürde yer almaktadır. ${ }^{[36]}$ Weiner ve ark. ise PKOS ve sağlıklı kontrollerde serbest testosteron seviyesi ile depresyon arasında lineer olmayan bir ilişki olduğunu göstermişlerdir. ${ }^{[34]}$

Yapılan birçok çalışmada, hipoaktif seksüel istek bozukluğu olan, doğal yolla veya cerrahi olarak menapoza girmiş kadınlar ile premenapozal kadınlara androjen içeren preparatların verilmesiyle libidoda artma olduğu gösterilmiştir. ${ }^{[8,9,37-39]}$ Hatta premenapozal sağlıklı kadınlara verilen testosteron tedavisi sonrasında seksüel istekte artma gözlenmiştir. ${ }^{[1]}$ Çalışmamızda libido düşüklüğüne neden olabilecek depresyon gibi güçlü bir faktör olmasına rağmen PKOS grubundaki kadınların libidosunun etkilenmediği tespit edilmiştir. Yüksek androjen seviyesi ile seksüel istek sıklığı arasında bir korelasyon olduğu saptanmıştır. ${ }^{[24]}$ Yapılan diğer çalışmalarda da yüksek testosteron düzeylerinin bir sonucu olarak PKOS'lu kadınların hirsutizm ve akne gibi kendilerini daha az çekici hissetmelerine sebep olabilecek birçok faktör olmasına rağmen hiperandrojenizmin seksüel fonksiyon açısından koruyucu bir faktör olarak rol oynayabileceği öne sürülmüştür. ${ }^{[28,40]}$ İstatistiki olarak olmasa da PKOS’ lu kadınların SAİ ile seksüel fonksiyon skoru arasında ilişki olduğunu gösteren çalışma mevcuttur. ${ }^{[21]}$ Androjen düzeyleri ile seksüel fonksiyon arasındaki ilişkiyi tespit edemesek de yüksek andojen seviyelerinin seksüel fonksiyon üzerine olumlu yönde etkileri olabileceğini düşünmekteyiz.

Çalışmamızda PKOS grubunda seksüel ağrı skorlamasının kontrol grubuna göre anlamlı oranda düşük olduğu bulunmuştur. Hastalarımızın genital herpes, vulvit, vulvovajinit, pelvik inflamatuvar hastalıklar, endometriosis gibi seksüel ağrıya yol açabilecek nedenler açısından ayrıntılı jinekolojik muayenelerinin yapılmamış olması çalışmanın eksik yönünü oluşturmaktadır. Ayrıca çalışmamızın kısıtlılıklarından biri de sonuçların istatistiksel anlamlılığını sınırlayabilecek olan hasta sayımızın azlığıdır. Literatürde, PKOS'lu Türk kadınlarında seksüel fonksiyonu değerlendiren az sayıda çalışma bulunmaktadır.

Sonuç olarak, PKOS hastalarında seksüel istek, uyarılma, lubrikasyon, tatmin ve orgazm bozuklukları ile ilgili skorlar kontrol bireylerdekine benzer, depresyon ile ilgili skorlar ise kontrol bireylere göre daha yüksek görülmektedir. Total FSFI, istek, uyarılma, lubrikasyon, orgazm, seksüel tatmin skorlamaları ile androjen seviyeleri arasında korelasyon tespit edilmemiştir.

\section{Etik Kurul Onayı}

Çalışma, İstanbul Üniversitesi, Cerrahpaşa Tıp Fakültesi Klinik Araştırmalar Etik Kurulu tarafından onaylandı. (onay tarihi ve sayısı: 06.01.2009/3935).

\section{Hakem Değerlendirmesi}

Dış bağımsız.

\section{Çıkar Çatışması}

Yazarlar çıkar ilişkisi olmadığını beyan etmişlerdir.

Finansal Destek

Çalışma, Bilimsel Araştırma Projesi (BAP) tarafından desteklenmiştir. Proje no: TTU-20082808.

\section{Ethics Committee Approval}

The study was approved by Istanbul University Cerrahpasa Medical Faculty Clinical Research Ethics Committee. (date and number of approval: 06.01.2009/3935).

\section{Peer-review}

Externally peer-reviewed.

Conflict of Interest

No conflict of interest was declared by the authors.

Financial Disclosure

The study was supported by the Scientific Research Project (BAP). Project no:TTU-20082808.

\section{KAYNAKLAR}

1. Norman RJ, Dewailly D, Legro RS, Hickey TE. Polycystic ovary syndrome. Lancet 2007 25;370:685-97. [CrossRef]

2. Azziz R. Polycystic Ovary Syndrome. Obstet Gynecol 2018;132:321-36. [CrossRef]

3. Tsilchorozidou T, Overton C, Conway GS. The pathophysiology of polycystic ovary syndrome. Clin Endocrinol (Oxf) 2004;60:117. [CrossRef] 
4. Rotterdam ESHRE/ASRM-Sponsored PCOS Consensus Workshop Group. Revised 2003 consensus on diagnostic criteria and long-term health risks related to polycystic ovary syndrome. Fertil Steril 2004;81:19-25. [CrossRef]

5. Conway G, Dewailly D, Diamanti-Kandarakis E, Escobar-Morreale HF, Franks S, Gambineri A, et al. The Polycystic Ovary Syndrome: an Endocrinological Perspective from the European Society of Endocrinology. Eur J Endocrinol 2014;171:P1-29. [CrossRef]

6. Vegunta S, Kling JM, Kapoor E. Androgen Therapy in Women. J Womens Health (Larchmt) 2020;29:57-64. [CrossRef]

7. Braunstein GD. Androgen insufficiency in women. Growth Horm IGF Res 2006;16:109-17. [CrossRef]

8. Cappelletti M, Wallen K. Increasing women's sexual desire: The comparative effectiveness of estrogens and androgens. Horm Behav 2016;78:178-93. [CrossRef]

9. Buster JE, Kingsberg SA, Aguirre O, Brown C, Breaux JG, Buch $A$, et al. Testosterone patch for low sexual desire in surgically menopausal women: a randomized trial. Obstet Gynecol 2005;105:944-52. [CrossRef]

10. Guay AT. Decreased testosterone in regularly menstruating women with decreased libido: a clinical observation. J Sex Marital Ther 2001;27:513-9. [CrossRef]

11. Motta-Mena NV, Puts DA. Endocrinology of human female sexuality, mating, and reproductive behavior. Horm Behav 2017;91:19-35. [CrossRef]

12. Tuiten A, Van Honk J, Koppeschaar H, Bernaards C, Thijssen J, Verbaten R. Time course of effects of testosterone administration on sexual arousal in women. Arch Gen Psychiatry 2000;57:149-53;discussion 155-6. [CrossRef]

13. Thannickal A, Brutocao C, Alsawas M, Morrow A, Zailem F, Murad MH, et al. Eating, sleeping and sexual function disorders in women with polycystic ovary syndrome (PCOS): A systematic review and meta-analysis. Clin Endocrinol (Oxf) 2020;92:338 49. [CrossRef]

14. Bhasin S, Enzlin P, Coviello A, Basson R. Sexual dysfunction in men and women with endocrine disorders. Lancet 2007 17;369:597-611. [CrossRef]

15. Janssen OE, Hahn S, Tan S, Benson S, Elsenbruch S. Mood and sexual function in polycystic ovary syndrome. Semin Reprod Med 2008;26:45-52. [CrossRef]

16. Rosen R, Brown C, Heiman J, Leiblum S, Meston C, Shabsigh R, et al. The Female Sexual Function Index (FSFI): a multidimensional self-report instrument for the assessment of female sexual function. J Sex Marital Ther 2000;26:191-208. [CrossRef]

17. Çayan S, Akbay E, Bozlu M, Canpolat B, Acar D, Ulusoy E. The prevalence of female sexual dysfuncion and potential risk factors that may impair sexual dysfunction in Turkish women. Urol Int 2004;72:52-7. [CrossRef]

18. Beck AT, Ward CH, Mendelson M, Mock J, Erbaugh J. An inventory for measuring depression. Arch Gen Psychiatr 1961;4:561-71. [CrossRef]

19. Anger JT, Brown AJ, Amundsen CL. Sexual Dysfunction in Women With Polycystic Ovary Syndrome: The Effect of Testosterone, Obesity and Depression. J Pelvic Med Surg 2007;13:119-24. [CrossRef]

20. Elsenbruch S, Hahn S, Kowalsky D, Offner AH, Schedlowski M, Mann K, Janssen OE. Quality of life, psychosocial well-being, and sexual satisfaction in women with polycystic ovary syndrome. J Clin Endocrinol Metab 2003;88:5801-7. [CrossRef]

21. Amiri FN, Tehrani FR, Esmailzadeh S, Tohidi M, Azizi F, Basirat Z. Sexual function in women with polycystic ovary syndrome and their hormonal and clinical correlations. Int J Impot Res 2018;30:54-61. [CrossRef]

22. Battaglia C, Nappi RE, Mancini F, Cianciosi A, Persico N, Busacchi P, et al. PCOS, sexuality, and clitoral vascularization: a pilot study. J Sex Med 2008;5:2886-94. [CrossRef]
23. Drosdzol A, Skrzpulec V, Mazur B, Pawlinska-Chmara R. Quality of life and marital sexual satisfaction in women with polycystic ovary syndrome. Folia Histochem Cytobiol 2007;45:S93-7. https://pubmed.ncbi.nlm.nih.gov/18292843/

24. Stovall DW, Scriver JL, Clayton AH, Williams CD, Pastore LM. Sexual Function in Women with Polycsytic Ovary Syndrome. J Sex Med 2012;9:224-30. [CrossRef]

25. Hahn S, Janssen OE, Tan S, Pleger K, Mann K, Schedlowski M, et al. Clinical and psychological correlates of quality-of-life in polycystic ovary syndrome. Eur J Endocrinol 2005;153:853-60. [CrossRef]

26. Ferraresi SR, da Silva Lara LA, Reis RM, de Sá Rosa e Silva ACJ. Changes in Sexual Function among Women with Polycystic Ovary Syndrome: A Pilot Study. J Sex Med 2013;10:467-73. [CrossRef]

27. Noroozzadeh M, Ramezani Tehrani F, Sedigh Mobarakabadi S, Farahmand M, Rostami Dovom M. Sexual function and hormonal profiles in women with and without polycystic ovary syndrome: a population-based study. Int J Impot Res 2017;29:1-6. [CrossRef]

28. Ercan CM, Coksuer H, Aydogan U, Alanbay I, Keskin U, Karasahin KE, Baser I. Sexual dysfunction assessment and hormonal correlations in patients with polycystic ovary syndrome. Int J Impot Res 2013;25:127-32. [CrossRef]

29. Demir B, Pasa S, Demir S, Tumer C, Atay AE, Gul T, Atamer Y. Hirsutism Score and the Severity of Hyperandrogenism Associated with Polycystic Ovary Syndrome in the South-eastern Region of Turkey. J Int Med Res 2011;39:1529-35. [CrossRef]

30. Lamont J, Bajzak K, Bouchard C, Burnett M, Byers S, Cohen T, et al. V. No 279-Female Sexual Health Consensus Clinical Guidelines. J Obstet Gynaecol Can 2018;40:E451-503. [CrossRef]

31. Chedraui P, Perez-Lopez FR. Assessing sexual problems in women at midlife using the short version of the female sexual function index. Maturitas 2015;82:299-303. [CrossRef]

32. Alur-Gupta S, Chemerinski A, Liu C, Lipson J, Allison K, Sammel MD, Dokras A. Body-image distress is increased in women with polycystic ovary syndrome and mediates depression and anxiety. Fertil Steril 2019;112:930-8.e1. [CrossRef]

33. Barnard L, Ferriday D, Guenther N, Strauss B, Balen AH, Dye L. Quality of life and psychological well being in polycystic ovary syndrome. Hum Reprod 2007;22:2279-86. [CrossRef]

34. Weiner CL, Primeau M, Ehrmann DA. Androgens and mood dysfunction in women: comparison of women with polycystic ovarian syndrome to healthy controls. Psychosom Med 2004;66:356-62. [CrossRef]

35. Rasgon NL, Rao RC, Hwang S, Altshuler LL, Elman S, Zuckerbrow-Miller J, Korenman SG. Depression in women with polycystic ovary syndrome: clinical and biochemical correlates. J Affect Disord 2003;74:299-304. [CrossRef]

36. Milaneschi Y, Simmons WK, van Rossum EFC, Penninx BW. Depression and obesity: evidence of shared biological mechanisms. Mol Psychiatry 2019;24:18-33. [CrossRef]

37. Sherwin BB, Gelfand MM, Brender W. Androgen enhances sexual motivation in females: a prospective, crossover study of sex steroid administration in the surgical menopause. Psychosom Med 1985;47:339-51. [CrossRef]

38. Shifren JL, Davis SR, Moreau M, Waldbaum A, Bouchard C, DeRogatis L, et al. Testosterone patch for the treatment of hypoactive sexual desire disorder in naturally menopausal women: results from the INTIMATE NM1 Study. Menopause 2006;13:770-9. [CrossRef]

39. Simon J, Braunstein G, Nachtigall L, Utian W, Katz M, Miller $S$, et al. Testosterone patch increases sexual activity and desire in surgically menopausal woman with hypoactive sexual desire disorder. J Clin Endocrinol Metab 2005;90:5226-33. [CrossRef]

40. Veras AB, Bruno RV, De Avila MA, Nardi AE. Sexual dysfunction in patients with polycystic ovary syndrome: clinical and hormonal correlations. Compr Psychiatry 2010;52:486-9. [CrossRef] 